\title{
Development and Validation of the SDDS-PC Screen for Multiple Mental Disorders in Primary Care
}

\author{
W. Eugene Broadhead, MD, PhD; Andrew C. Leon, PhD; Myrna M. Weissman, PhD; \\ James E. Barrett, MD; Robert S. Blacklow, MD; Thomas T. Gilbert, MD, MPH; \\ Martin B. Keller, MD; Mark Olfson, MD; Edmund S. Higgins, MD
}

Objective: To develop, validate, and cross-validate a patient-completed screen for multiple mental disorders in primary care.

Design: Comparison of a patient self-report screen with an independent diagnostic assessment by mental health professionals using the Structured Clinical Interview for DSM-III-R diagnoses as criterion standard.

Setting: Three Rhode Island family practices and a South Carolina family medicine residency.

Subjects: In the initial validation study, 937 patients in Rhode Island were screened; 388 were interviewed. In the cross-validation study, 775 patients were screened in Rhode Island and South Carolina, and 257 were interviewed.

Sereen Ifems: Sixty-two questions pertaining to nine mental disorders and suicidal ideation.

Results: A 16-item screen remained after analysis of item and scale performance. Sensitivity, specificity, and positive predictive value, respectively, were calculated for the following scales: alcohol abuse or dependence $(62 \%, 98 \%$, and $54 \%)$, generalized anxiety disorder $(90 \%, 54 \%$, and $5 \%$, major depression $(90 \%, 77 \%$, and $40 \%)$, obsessivecompulsive disorder $(65 \%, 73 \%$, and $5 \%)$, panic disor$\operatorname{der}(78 \%, 80 \%$, and $21 \%)$, and suicidal ideation ( $43 \%$, $91 \%$, and $51 \%$ ). Replication in a new sample showed attenuated but acceptable operating characteristics for crossvalidation.

Conclusions: The Symptom-Driven Diagnostic System for Primary Care screen assesses multiple mental disorders that are common to primary care. It serves as a sensitive, valid, and patient-friendly first step in a new approach to recognizing and managing mental disorders in primary care. Finally, it aids the primary care clinician in selecting an appropriate diagnostic interview module for the disease for which the patient screened positive.

(Arch Fam Med. 1995;4:211-219)
From Duke University Medical Center, Durham, NC (Dr Broadhead); Cornell University Medical College (Dr Leon), the College of Physicians and Surgeons, Columbia University(Drs Weissman and Olfson), and the New York State Psychiatric Institute (Drs Weissman and Olfson), New York, NY; Dartmouth Medical School, Hanover, $\mathrm{NH}$ (Dr Barrett); Northeastern Ohio Universities College of Medicine, Rootstown, $\mathrm{OH}$ (Dr Blacklow); Brown University, Providence, RI (Drs Gilbert and Keller); and the Medical University of South Carolina, Charleston (Dr Higgins)

Drs Broadhead, Leon,

Weissman, Barrett, Keller, Olfson, and Higgins have served as consultants to the UpJohn Co, Kalamazoo, Mich.

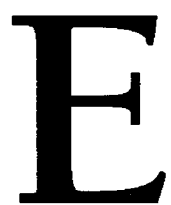

STIMATES OF the prevalence of mental disorders in primary care practice vary from $9 \%$ to $35 \%{ }^{1-3}$ Data from the 1980 and 1981 National Ambulatory Medical Care Survey show that almost half of the office visits that result in the diagnosis of a mental disorder are to nonpsychiatric physicians. ${ }^{4}$ The Epidemiologic Catchment Area study data show that nearly half of the individuals with mental or addictive disorders who receive treatment are seen in the general medical sector (usually by primary care physicians). ${ }^{5}$ Yet, a review of the medical literature reveals that these conditions are often unrecognized, untreated, or undertreated. ${ }^{6}$ For example, the morbidity of depression ${ }^{7-9}$ and the economic burden of depression and anxiety have been well described in the literature. ${ }^{10-12}$ However, recognition rates by primary care physicians of less than $50 \%$ for major depression are consistently found, ${ }^{3,13}$ except in the most severe cases. ${ }^{14}$ Primary care physicians appear to undertreat patients with mental disorders frequently or to overtreat patients by prescribing psychotropic drugs without psychiatric indications. ${ }^{4,15-20}$

Screening questionnaires have been developed to try to improve recognition of mental disorders in primary care practice. These questionnaires either àssess general distress, such as the General Health Questionnaire, ${ }^{21-24}$ or symptoms of specific mental disorders, ${ }^{25-30}$ but they do not screen for multiple specific mental disorders simultaneously.

Arguments against screening include the lack of proven long-term benefit, ${ }^{31}$ the psychological risk of false-positive test results, harm to society-at-large by theoretically decreasing compliance with more proven screening tests for other disorders, and harming the physician-patient interaction. ${ }^{32}$ Those in favor of using screening 
Table 1. Number of Items on Prototype and Final Versions of the Screening Questionnaire for Each Disorder of Interest*

\begin{tabular}{lcc}
\hline Disorder & $\begin{array}{c}\text { 62-Item } \\
\text { Prototype } \\
\text { Version }\end{array}$ & $\begin{array}{c}\text { 16-Item } \\
\text { Final } \\
\text { Version }\end{array}$ \\
\hline Alcohol abuse and dependence & 3 & 2 \\
Agoraphobia (without panic) $\dagger$ & 3 & 0 \\
Drug abuse & 2 & 0 \\
Generalized anxiety disorder & 3 & 2 \\
Major depression & 26 & 5 \\
Panic disorder & 6 & 3 \\
Obsessive-compulsive disorder & 4 & 2 \\
Social phobiat & 2 & 0 \\
Somatization† & 10 & 0 \\
Suicidal ideation & 3 & 2 \\
\hline
\end{tabular}

* Values are the number of items for a given scale.

$\dagger$ Removed from the final questionnaire.

questionnaires are ambivalent at best ${ }^{33}$ or advocate for the potential use of questionnaires as case finders for mental disorders only among patients who have a greater prior probability of disorder ${ }^{34}$ rather than advocating screening of the general patient population. Neither the Canadian Task Force on the Periodic Health Examination ${ }^{35}$ nor the US Preventive Services Task Force ${ }^{36}$ recommend screening for depression (the most commonly studied disorder) with established screening questionnaires. Screening is recommended for alcoholism but not for other mental disorders. $^{36}$

However, clinical trials have shown that feedback from screening questionnaire data can significantly improve the rate of physician recognition of depression, ${ }^{37-40}$ the rate of treatment of mental disorders, ${ }^{40,41}$ and patient outcomes. ${ }^{41}$ Naturalistic studies also have demonstrated that recognition and treatment of depression by primary care physicians improved outcomes, but this appears to be restricted to those with concomitant anxiety disorders. ${ }^{14,42}$

Potential explanations for the equivocal success of screening questionnaires include their limitation to single disorders when multiple mental disorders are possible and present in primary care patients and the absence of diagnostic criteria. Two newly developed systems, the PRIME-MD (Primary Care Evaluation of Mental Disorders $)^{43}$ and The Symptom-Driven Diagnostic System for Primary Care (SDDS-PC) (The UpJohn Co, Kalamazoo, Mich), are designed to screen for multiple common mental disorders in primary care and include, in a second stage, the application of diagnostic criteria. Both systems have been developed with the intent to increase the primary care physicians' diagnostic accuracy and, thus, the usefulness and likelihood of use of the system.

\section{See also page 208}

In the SDDS-PC, a brief screen for multiple mental disorders is linked to a group of brief disorder-specific, criterionbased interview modules, which include medical "rule outs." These modules are based on Diagnostic and Statistical Manual of Mental Disorders, Revised Third Edition (DSM-III-R) ${ }^{44}$ criteria for each mental disorder and assist the physician in mak- ing specific mental disorder diagnoses. The screen scores for the diagnoses indicate which modules are appropriate to use. The screen is designed to be a brief, easy to use, and efficient way to simultaneously screen for multiple mental disorders in a primary care setting. The screen results can be followed by the appropriate confirmatory test: a brief structured interview by the patient's own physician or nurse.

The principal objectives of the two studies reported herein were to develop the brief screen and then to test its validity. Thus, two independent studies were conducted: an initial screen validation study and a cross-validation study. The design of the second study was based on the results of the first.

\section{STUDY 1: THE INITIAL SCREEN VALIDATION STUDY}

\section{Methods}

Subjects and Sampling. The initial screen validation study was conducted in the spring and summer of 1992 in three private family practice offices in cooperation with the Departments of Family Medicine and Psychiatry of Brown University, Providence, RI. The six full-time and one part-time board-certified family physicians and two nurse practitioners served both urban and suburban populations drawn from Rhode Island and neighboring Massachusetts. All consenting patients between 18 and 70 years of age who were able to read and write English were eligible. Pregnant women were excluded, as well as patients who did not have a face-to-face visit with the physician (eg, patients who only had laboratory work done). No patient was included in the sample twice.

A two-stage assessment procedure was used. Research assistants rotated between the three waiting rooms, and during their assigned recruitment times, they approached all possible eligible patients before patient visits with the physician. Recruitment times were assigned based on the availability of the research assistants. All consenting eligible patients were first screened and then asked to participate in a diagnostic interview (the Structured Clinical Interview for the DSM-III-R, ${ }^{45,46}$ version P [SCID-P]). Screens were scored while the patients were seeing their physicians. Afterward, for the subset of consenting patients, the research assistants scheduled interviews with the SCID-P interviewers, who did not have prior knowledge of the patients' screen scores or the diagnoses made by the physicians. Patients from two of the Rhode Island family practices underwent in-person SCID-P interviews at the Brown University Department of Psychiatry nearby. Patients from the third practice were interviewed with the SCID-P at that office during periods of low patient volume. The SCID-P interviews were scheduled to be conducted as soon as possible but no later than 2 weeks after the initial screening questionnaire.

The Initial Screening Questionnaire. The prototype screening questionnaire included 62 items designed to be brief and easy to read, with yes and no answers based on a 1-month symptom recall window. Items were selected from a pool of questions used to screen patients for family genetic studies conducted by one of us (M.M.W.). Additional items were developed by us and selected through the use of focus groups of primary care physicians. Table $\mathbf{I}$ 
lists the 10 psychiatric diagnoses of interest, and the number of items on the prototype screening questionnaire expected to relate to each diagnosis.

Diagnostic Criteria. The diagnostic standard for this study was the SCID ${ }^{45,46}$ which has a standardized format designed for use by mental health professionals in making psychiatric diagnoses according to the DSM-III-R. For this study, the SCID-P version, which was developed by Michael First, MD, J. Williams DSW, R. Spitzer, MD, and M. Gibbon, PhD (unpublished data, 1991) for the Diagnostic and Statistical Manual of Mental Disorders, Fourth Edition (DSM-IV) ${ }^{47}$ dysthymia and major depression field trial, was used. For each of the disorders listed in Table 1 and for each patient, it was ascertained whether that disorder was present in the last month, with the exception of generalized anxiety disorder (GAD), for which a 6-month period was used.

Reflecting the comorbidity or coexistence of mental disorders in any population, some patients screened positive for one or more disorders or met the criteria for one or more SCID-P diagnoses. As a result, patients could be used in the analysis of operating characteristics for more than one diagnosis.

Training took place under the supervision of one of us (M.B.K.) in the Department of Psychiatric and Human Sciences at Brown University School of Medicine. Three of the five interviewers had master's degrees in psychology or counseling, and the two interviewers with bachelor's degrees had extensive clinical experience in these areas. Training generally involved instructional videos and 4 days of didactic training, mock interviews with feedback, observation of interviews, and testing using training videotapes as standards. Throughout the study, all interviews were edited for clinical and clerical accuracy, and feedback and suggestions regarding diagnostic issues were given to the interviewers as necessary.

Additional Validity Criteria. General construct validity criteria for all the diagnoses were three social impairment items that were developed for studies of genetic epidemiology by one of us (M.M.W.) and that address patient assessment of the following factors within the past month: their own emotional health, whether they had missed work or school or were unable to do housework because of emotional problems, and whether they got along with their spouse or partner. The Global Assessment Scale, ${ }^{48}$ a self-rating of overall functioning on a scale of 0 to 100 , also was used to examine the construct validity of the screens.

As a specific construct validity criterion for the disorder of major depression, the Burnam depression scale, ${ }^{49}$ an eight-item screen for depression that was developed for the Medical Outcomes Study, ${ }^{50}$ was used. As a specific construct validity criterion for alcoholism or alcohol abuse, the four $\mathrm{CAGE}^{51}$ (cutting down, annoyance by criticism, guilty feeling, and eye openers) questions were given in a self-administered format.

Finally, information was obtained on patient attitudes about the questionnaire from a survey designed by the authors for this study.

Statistical Analyses. For each of the 10 disorders in Table 1 , all possible subsets of the symptoms identified in advance
Table 2. Demographic Distributions for Patients Screened With the SDDS-PC Screening Questionnaire in the Initial Validation and Cross-Validation Studies*

\begin{tabular}{|c|c|c|c|}
\hline Variable & $\begin{array}{c}\text { Initial } \\
\text { Validation } \\
\text { Studyt }\end{array}$ & $\begin{array}{l}\text { Cross- } \\
\text { Validation } \\
\text { Study }\end{array}$ & $P$ \\
\hline \multicolumn{4}{|l|}{ Sex, No. (\%) } \\
\hline $\mathrm{F}$ & $282(72.9)$ & $204(79.4)$ & $.06 \S$ \\
\hline M & $105(27.1)$ & $53(20.6)$ & \\
\hline \multicolumn{4}{|l|}{ Race, No. (\%) } \\
\hline W & $380(97.9)$ & $184(71.9)$ & $<.001 \S$ \\
\hline B & $1(0.3)$ & $67(26.2)$ & \\
\hline Other & $7(1.8)$ & $5(2.0)$ & \\
\hline \multicolumn{4}{|l|}{ Marital status, No. (\%) } \\
\hline Married & $246(64.4)$ & $126(49.6)$ & \\
\hline Living with someone & $20(5.2)$ & $21(8.3)$ & $.003 \S$ \\
\hline Widowed & $11(2.9)$ & $10(3.9)$ & \\
\hline Separated or divorced & $34(8.9)$ & $40(15.7)$ & \\
\hline Never married & $71(18.6)$ & $57(22.4)$ & \\
\hline \multicolumn{4}{|l|}{ Education, No. (\%) } \\
\hline Less than ninth grade & $6(1.6)$ & $12(4.7)$ & \\
\hline High school & $106(27.7)$ & $75(29.4)$ & $.001 \S$ \\
\hline Some college & $94(24.6)$ & $84(32.9)$ & \\
\hline Graduated college & $176(46.1)$ & $84(32.9)$ & \\
\hline Age, y (mean $\pm S D)$ & $39.4 \pm 12.4$ & $40.3 \pm 13.2$ & $.38 \|$ \\
\hline
\end{tabular}

*SDDS-PC (The UpJohn Co, Kalamazoo, Mich) indicates

Symptom-Driven Diagnostic System for Primary Care.

$\dagger$ Took place in Rhode Island.

$\ddagger$ Took place in Rhode Island and South Carolina.

$\S \mathrm{P}$ value obtained using the $x^{2}$ test.

$\| \mathrm{P}$ value obtained using the $\mathrm{t}$ test.

by us as relevant for each disorder were examined. The patient's score for each subset was the number of items in the subset that were endorsed by the patient. The best subset of items for each diagnosis was selected in the following manner: each subset and each possible cutoff point for the resulting score were evaluated against the corresponding diagnostic criterion diagnosis for sensitivity, specificity, positive predictive value (PPV), and negative predictive value. Because of the large number of depression symptoms, only those symptoms that were most strongly associated with the SCID-P diagnosis (10 of 26 items based on stepwise logistic regression analysis) were examined in these analyses. The operating characteristics were calculated using the algorithms presented in $\mathrm{Kraemer}^{52}$ for a prospective design. This strategy was used because a subset of patients who were screened also received the SCID-P. For each diagnosis, the choice of the best test (selection of items and cutoff points used to describe a positive screen result) was made to optimize sensitivity, specificity, and PPV while minimizing the number of items used. If the performance of the prototype was uniformly poor for all subsets of items of a diagnosis, it was removed from further consideration.

\section{Results}

Patient Flow and Characteristics. A total of 1360 patients were approached to participate, and 937 were screened (a consent rate of $69 \%$ ). Face-to-face SCID-P interviews were completed with 388 patients ( $29 \%$ of those approached, or $41 \%$ of those screened) in the initial validation study. Nonrespondents included those who made 
direct refusals, missed appointments, or could not be contacted within 2 weeks. A comparison of those who were screened but not interviewed with those who were interviewed revealed no significant differences in age, gender, or education. Nonwhites were less likely $(27 \%)$ to be interviewed than were whites $(40 \%)(P=.007)$. Single persons were less apt to be interviewed (34\%) than were married persons $(43 \%)(P=.03)$.

The SCID-P interview took place within 14 days for $50 \%$ of the patients. The patients who were interviewed in the initial validation study (Table 2) were mostly female $(72 \%)$, white $(98 \%)$, and married (59\%). Most had some college education $(67 \%)$. Their mean age was 38.5 years.

Most patients ( $84 \%$ ) believed that the initial screening questionnaire would help their physicians; $45 \%$ thought that it was helpful to themselves. Completion of the assessment package, which included demographic questions, the Burnam questionnaire, additional questions on depression, CAGE questions, social impairment questions, and patient opinions, took 10 to 15 minutes for $87 \%$ of the patients. Most patients (93\%) did not find the assessment package confusing; $22 \%$ thought it was too long.

Selection of Items. Four of the diagnoses (agoraphobia without panic disorder, drug abuse, social phobia, and somatoform disorder) could not be identified easily using the prototype SDDS-PC screen questions. These diagnoses had poor sensitivities or PPVs and therefore were eliminated from further consideration in this study. For the remaining six disorders, the items selected and the best cutoff points are presented in Table 3 . The selection procedure reduced the list of items used in the validation study to $\mathbf{1 6}$ from the 62 items that were tested in the prototype. The 16 items listed in Table 3 are, word for word, identical to the questionnaire, which has yes and no boxes in which the patients can mark their responses. The questions were, however, in random order.

Performance Characteristics. Sensitivity, specificity, PPV, negative predictive value, efficiency, and Cohen's $\kappa$ for the resulting 16-item screen are presented separately for each disorder in Table 4.

The co-occurrence of other SCID-P diagnoses was examined for the two diagnoses with the lowest screen PPVs. Forty-one percent of the patients with a falsepositive screen result for GAD had another SCID-P diagnosis or significant suicidal ideation. Patients with falsepositive screen results for obsessive-compulsive disorder (OCD) had another SCID-P diagnosis or significant suicidal ideation $50 \%$ of the time.

Further Validity Results. The SDDS-PC depression and alcoholism screens were compared with two existing screens in Table 5. Patients with SCID-P major depression or positive SDDS-PC depression screen results had higher Burnam depression scale scores than did patients without major depression or with negative screen results for depression. Patients with SCID-P alcohol abuse or dependence or positive SDDS-PC alcohol abuse or dependence screen results had higher CAGE scores than did those with negative screen results or those who did not have SCID-P diagnoses of alcohol abuse or dependence.
Table 3. Sixteen SDDS-PC Screen Items and Cutoff Points*

\begin{tabular}{|c|c|c|}
\hline Disorder & Items† & Cutoff Points \\
\hline $\begin{array}{l}\text { Alcohol abuse and } \\
\text { dependence }\end{array}$ & $\begin{array}{l}\text { Drinking in the morning } \\
\text { Drinking too much }\end{array}$ & Any 1 item \\
\hline $\begin{array}{l}\text { Generalized anxiety } \\
\text { disorder }\end{array}$ & $\begin{array}{l}\text { Anxiety } \\
\text { Nervousness }\end{array}$ & Any 1 item \\
\hline Major depression & $\begin{array}{l}\text { Crying } \\
\text { Feeling sad or bluef } \\
\text { Unhappiness } \\
\text { Loss of pleasure }\end{array}$ & Any 2 items \\
\hline $\begin{array}{l}\text { Obsessive-compulsive } \\
\text { disorder }\end{array}$ & $\begin{array}{l}\text { Cleaning things over } \\
\text { and over } \\
\text { Same thoughts over } \\
\text { and over }\end{array}$ & Any 1 item \\
\hline Panic disorder & $\begin{array}{l}\text { Fear } \\
\text { Fear of crowds } \\
\text { Sudden panic attack }\end{array}$ & Any 1 item \\
\hline Suicidal ideation & $\begin{array}{l}\text { Wishing you were dead } \\
\text { Thoughts of death }\end{array}$ & Any 1 item \\
\hline
\end{tabular}

*SDDS-PC (The UpJohn Co, Kalamazoo, Mich) indicates Symptom-Driven Diagnostic System for Primary Care.

†Sixteen items selected from the 62-item prototype by a best subset analysis. Items are listed verbatim from the questionnaire where they are used in a yes or no format.

$\ddagger$ For analyses purposes, the items "feeling sad" and "feeling blue" were combined.

The performance of the six SDDS-PC subtests in comparison with the general validation criterion of global functioning is presented in Table $\mathbf{6}$. For each diagnosis, those with positive screen results were functioning at significantly lower levels than those with negative results. The presence of one or more functional impairments is shown for major depression and panic disorder in Table 7. Patients with positive screen results for a given disorder or patients who had the disorder had higher rates of having one or more impairments.

\section{STUDY 2: THE CROSS-VALIDATION STUDY}

\section{Methods}

Subjects and Sampling. The cross-validation study done in the winter and spring of 1993 used the same eligibility criteria. It was conducted at two sites: the same Rhode Island practices as were used in the initial validation study and the family medicine residency practice of 10 medical residents who were associated with the Medical University of South Carolina, Charleston. Patients who had previously participated in the initial validation study were excluded from the cross-validation study at Brown University. The data reported herein were collected as part of a larger study evaluating the second step of the SDDSPC, ie, modular diagnostic interviews for suicidal ideation and five diagnoses covered by the SDDS-PC screen.

Procedures for screening patients from the Rhode Island site were the same as those done in the initial validation study. The South Carolina site had one research assistant who recruited eligible patients from a few physicians' practices within the residency program on any given sampling day.

Unlike the initial validation study, a two-stage sampling method was used to select patients to interview based on the 


\begin{tabular}{lccrrrr}
\hline Test & Sensitivity, $\%$ & Specificity, $\%$ & PPV, $\%$ & NPV, \% & \multicolumn{1}{c}{ Efficiency, \% } \\
\hline Alcohol abuse and dependence $(n=12)$ & 61.8 & 98.2 & 53.8 & 98.7 & 96.9 & 56.0 \\
Generalized anxiety disorder $(n=12)$ & 89.8 & 54.0 & 5.4 & 99.5 & 55.0 & 5.1 \\
Major depression ( $n=61)$ & 90.4 & 77.2 & 39.7 & 98.0 & 79.1 & 44.1 \\
Obsessive-compulsive disorder $(n=8)$ & 64.5 & 72.5 & 5.1 & 98.9 & 72.4 \\
Panic disorder $(n=27)$ & 78.3 & 80.0 & 20.8 & 98.2 & 79.9 \\
Suicidal ideation ( $n=70)$ & 43.6 & 90.6 & 50.8 & 87.8 & 82.1 \\
\hline
\end{tabular}

*SDDS-PC (The UpJohn Co, Kalamazoo, Mich) indicates Symptom-Driven Diagnostic System for Primary Care; SCID-P, Structured Clinical Interview for the Diagnostic and Statistical Manual of Mental Disorders, Revised Third Edition, version P; PPV, positive predictive value; and NPV, negative predictive value. $\dagger n$ indicates the number of patients with this SCID-P diagnosis. A two-staged sampling strategy was used to select the sample that received the SCID-P. For that reason, prevalence estimates could not be obtained directly from these data. In a forthcoming manuscript, Bayesian procedures will be applied to make such estimates.

screening results. All who tested positive for a disorder on the screening test and a random sample of those who tested negative for the disorders were asked to complete the SCID-P interview.

The Screening Questionnaire. In this study, a 54-item screen was used that included all 16 items selected in the initial validation study just presented. The 54 items were a subset of the original 62; item selection was based on internal consistency analyses. The definition of a positive test result for each disorder accords with that presented in Table 3.

Diagnostic Criteria. The diagnostic criteria were the same as those in the initial validation study. The three SCID-P interviewers in South Carolina received the same training as the Rhode Island SCID-P interviewers. In South Carolina, a pilot study of 17 interviews was audiotaped and reviewed by the trainer from Brown University to ensure crosssite comparability. Feedback provided further training and adherence to a standard interviewing technique across both sites. Interviews were scheduled so that they would be completed within 72 hours. Patients were asked to complete an in-person interview or were offered a telephone interview if the in-person interview was not possible within the allotted time. The validity of telephone interviews in psychiatric disorders has been well documented..$^{53-55}$

\section{Results}

Patient Flow and Characteristics. A total of 2089 subjects were approached, of whom 775 (37\%) agreed to be screened and 257 (12\%) completed the SCID-P. Table 2 presents the descriptors for patients who were screened in the cross-validation study. In the cross-validation study, $50 \%$ of the SCID-P interviews were completed within 5 days of the screen. Ninety-nine percent were completed within 14 days.

Cross-Validation Results. Table 8 includes the performance characteristics of the five SDDS-PC screens that were developed in the initial validation study.

\section{COMMENT}

To evaluate the potential usefulness of the SDDS-PC screen, it must first be determined whether it meets some basic requirements for screening tests:
1. It should be inexpensive and easy to provide for large numbers of people. A 16-item paper-and-pencil or computerized screen easily meets this criterion.

2. It must screen for disorders or conditions with one or more generally accepted and effective treatments. This is true of the five disorders studied herein. Suicidal ideation is managed as part of one or more of the other disorders.

3. Because of the serious consequences that mental disorders pose to society, the test must be highly sensitive, ie, a high proportion of all cases must be detected by the test. This is certainly true of the more prevalent depression and anxiety disorder components of the SDDS-PC screen, with only moderate sensitivities for alcohol abuse and OCD.

4. For disorders in which false-positive test results may lead to increased cost and inconvenience to the patient and society, as well as to an increased risk of iatrogenic illness resulting from further evaluation, a low rate of false-positive results (high PPV) is desirable. The PPVs for the SDDS-PC screen are reasonable for alcohol abuse, major depression, panic disorder, and suicidal ideation. The risk and inconvenience for those tests with lower PPVs (GAD and OCD) is low.

The SDDS-PC screen is not diagnostic and should only trigger the use of a more specific test, for example, the appropriate SDDS-PC diagnostic interview module. The diagnostic interview module component, still under evaluation (M.M.W., unpublished data, 1994), is also a low-cost pencil-and-paper or computerized assessment instrument. Its greatest cost is the 5 to 10 minutes needed for the clinician or nurse to administer the appropriate interview module(s) for the patient with a positive screen result. It does not entail referral to a psychiatrist or psychologist ${ }_{\mathbf{q}}$ nor does it involve medically risky or expensive diagnostic or therapeutic interventions such as endoscopy, biopsy, or radiography. Because the SDDS-PC screen is not diagnostic, the stigma of a mental disorder diagnosis in a patient without mental illness should not be an issue.

Another factor to consider in evaluating the SDDS-PC screen involves comparing it with other tests for mental disorders. The SDDS-PC screen has been compared with two general and non-disease-specific mental health checklists, the Hopkins Symptom Checklist ${ }^{23}$ and the General Health Questionnaire, ${ }^{26}$ at their standard cutoff points (in other samples). The sensitivities of the SDDS-PC screen 


\begin{tabular}{|c|c|c|c|c|}
\hline \multicolumn{5}{|c|}{$\begin{array}{l}\text { Table 5. Specific Validation Criteria: The Burnam and } \\
\text { CAGE Questionnaires in } 388 \text { Rhode Island Family Practice } \\
\text { Patients (Initial Validation Study)* }\end{array}$} \\
\hline \multirow[b]{2}{*}{ Test } & \multicolumn{2}{|c|}{ Test Result } & \multirow[b]{2}{*}{$t$} & \multirow[b]{2}{*}{$P$} \\
\hline & Negative & Positive & & \\
\hline \multicolumn{5}{|c|}{$\begin{array}{l}\text { Depression (Burnam Scale Scores) } \\
\end{array}$} \\
\hline SCID-P major depression & $0.05(0.13)$ & $0.39(0.32)$ & -8.07 & $<.001$ \\
\hline SDDS-PC depression & $0.02(0.04)$ & $0.25(0.29)$ & -9.50 & $<.001$ \\
\hline \multicolumn{5}{|c|}{$\begin{array}{l}\text { Alcohol (CAGE Scores) } \\
\end{array}$} \\
\hline $\begin{array}{l}\text { SCID alcohol abuse and } \\
\text { dependence }\end{array}$ & $0.31(0.79)$ & $2.00(1.60)$ & -3.65 & .004 \\
\hline $\begin{array}{l}\text { SDDS-PC alcohol abuse } \\
\text { and dependence }\end{array}$ & $0.30(0.78)$ & $2.31(1.11)$ & -6.48 & $<.001$ \\
\hline
\end{tabular}

*CAGE stands for cutting down, annoyance by criticism, guilty feeling, and eye openers; SCID-P, Structured Clinical Interview for the Diagnostic and Statistical Manual of Mental Disorders, Revised Third Edition, version $P$; and SDDS-PC (The UpJohn Co, Kalamazoo, Mich), Symptom-Driven Diagnostic System for Primary Care. Values in parentheses indicate SDS.

Table 6. General Validation Criteria: The Global Assessment Scale in a Screening Sample of 937 Patients in Rhode Island (Initial Validation Study)

\begin{tabular}{lcc}
\hline Diagnosis & $\begin{array}{c}\text { Negative } \\
\text { Result } \\
\text { of Screen }\end{array}$ & $\begin{array}{c}\text { Positive } \\
\text { Result } \\
\text { of Screen }\end{array}$ \\
\hline Alcohol abuse or dependence & $70.38(9.91)$ & $57.62(12.14)$ \\
Generalized anxiety disorder & $74.75(7.25)$ & $65.68(10.62)$ \\
Major depression & $74.13(7.50)$ & $62.65(10.30)$ \\
Obsessive-compulsive disorder & $72.62(9.05)$ & $63.71(10.17)$ \\
Panic disorder & $72.94(8.56)$ & $62.03(10.13)$ \\
Suicidal ideation & $70.91(9.60)$ & $64.58(11.98)$ \\
\hline
\end{tabular}

$* \mathrm{P}<.001$ for all diagnoses.

in the initial validation study (Table 4) were higher than the Hopkins Symptom Checklist and the General Health Questionnaire, respectively, reported for the major depression scale ( $90.4 \%$ vs $84.8 \%$ and $85.7 \%$ ) and the panic disorder scale ( $78.3 \%$ vs $45.5 \%$ and $55.8 \%$ for anxiety disorders) ${ }^{56}$ The alcohol abuse or dependence sensitivity is also greater $(61.8 \%$ vs $46.6 \%$ and $56.4 \%$ for all substance abuse disorders).$^{56}$

Finally, a comparison of the SDDS-PC screen with commonly used biomedical tests may permit a better assessment of its potential usefulness in primary care practice. Table $\boldsymbol{9}^{57-61}$ lists examples of five commonly used tests and their corresponding sensitivities and positive predictive values. The sensitivities of the SDDS-PC screen are all within the range of these generally accepted tests, and PPVs appear to be better overall, in comparison. However, the PPVs for OCD and GAD are nonetheless quite low.

Based on these general assessments of the SDDS-PC screen, it appears to be as good as existing mental health screens at meeting the requirements of a useful screening instrument. The SDDS-PC screen provides the further advantage of screening for multiple disorders in a very brief format, thereby giving it more utility in primary care than the existing single-disorder, longer screens. Some additional comments are necessary, however.
Table 7. General Validation Criteria: Functional Impairment (Rate per 100 Patients) for Major Depression and Panic Disorder (Initial Validation Study)*

\begin{tabular}{lcccc}
\hline Diagnosis & $\begin{array}{c}\text { Screen } \\
\text { Result }\end{array}$ & $\begin{array}{c}\text { SCID-P } \\
\text { Result } \dagger\end{array}$ & $\begin{array}{c}\text { No. of } \\
\text { Patients }\end{array}$ & $\begin{array}{c}\text { Rate of } \\
\text { Impairment }\end{array}$ \\
\hline Major depression & - & - & 239 & 15.5 \\
& - & + & 5 & 60.0 \\
Panic disorder & + & - & 82 & 53.7 \\
& + & + & 56 & 89.3 \\
& - & - & 273 & 24.5 \\
& + & + & 5 & 40.0 \\
& + & - & 82 & 58.5 \\
& + & + & 22 & 81.8
\end{tabular}

* Impairment rates are not shown for the other diagnoses, which occurred too infrequently to make meaningful comparisons. Minus sign indicates negative; plus sign, positive.

tComplete screen, Structured Clinical Interview for the Diagnostic and Statistical Manual of Mental Disorders, Revised Third Edition, version P (SCID-P), and impairment data are available on only 382 patients of the 937 screened.

$\ddagger$ Impairment is present if at least one of the following factors is endorsed: feeling in poor emotional health, missing work or school, or not getting along with partner.

The low sensitivity of the suicidal ideation screen indicates that this screen should not be used independently, apart from the rest of the 16 -item screen. Nor should it be used in the absence of an interview when suicidal ideation is suspected. However, the strong PPV of this screen gives it great potential when coupled with the three screens that are typically associated with suicide and suicidal ideation (major depression, alcohol abuse or dependence, and panic disorder) to assist the primary care clinician in detecting unsuspected suicidal ideation.

The PPV is a function of sensitivity, specificity, and prevalence. ${ }^{62}$ Thus, low PPVs for GAD and OCD largely may be due to the low prevalence of these disorders ( 12 cases and eight cases, respectively). Nevertheless, it is likely that in future applications, the majority of those who screen positive for GAD and OCD will have false-positive results. In addition, the GAD and $O C D$ screens are sensitive to other mental disorders in patients who do not have GAD or OCD. That is, when positive, the GAD and OCD screens are strong although nonspecific predictors of mental illness.

The low PPV of the GAD scale also in part may be due to the 1-month duration requirement for the screen vs the 6-month duration specification of the DSM-III-R and the SCID-P. A review of some patients who screenied positive for GAD but did not meet SCID-P diagnostic standards showed that many of these patients experienced the GAD symptoms but did not meet the duration criteria.

The screens for four diagnoses that are potentially relevant to primary care (agoraphobia, drug abuse, social phobia, and somatoform disorder) did not withstand the requirements of our test development procedures. This may be related to conceptual issues of detecting these disorders with a written test or to the brevity of the scales, which may not have permitted detection of a disorder with a broad array of presenting symptoms. For example, somatoform disorder that meets full DSM-III-R criteria is rare in primary care, so evaluation of the somatization scale against 
Table 8. Cross-Validation of Six SDDS-PC Screen Tests by SCID-P Diagnoses in 257 Family Practice Patients From Rhode Island and South Carolina*

\begin{tabular}{|c|c|c|c|c|c|c|}
\hline Test† & Sensitivity, $\%$ & Specificity, \% & PPV, \% & NPV, $\%$ & Efficiency, \% & $\kappa$ \\
\hline Alcohol abuse and dependence $(n=10)$ & 37.6 & 98.9 & 60.0 & 97.2 & 96.2 & 44.3 \\
\hline Generalized anxiety disorder $(n=14)$ & 84.8 & 59.8 & 10.5 & 98.6 & 61.1 & 10.3 \\
\hline Major depression $(n=47)$ & 66.6 & 82.7 & 43.0 & 92.7 & 80.0 & 40.4 \\
\hline Obsessive-compulsive disorder $(n=10)$ & 24.3 & 81.2 & 4.9 & 96.4 & 79.1 & 1.9 \\
\hline Panic disorder $(n=16)$ & 65.3 & 83.5 & 19.6 & 97.5 & 82.4 & 23.3 \\
\hline Suicidal ideation $(n=34)$ & 62.7 & 91.5 & 48.0 & 95.2 & 88.4 & 47.8 \\
\hline
\end{tabular}

*SDDS-PC (The UpJohn Co, Kalamazoo, Mich) indicates Symptom-Driven Diagnostic System for Primary Care; SCID-P, Structured Clinical Interview for the Diagnostic and Statistical Manual of Mental Disorders, Revised Third Edition, version P; PPV, positive predictive value; and NPV, negative predictive value.

t $n$ indicates the number of patients with this diagnosis according to the SCID-P. A two-staged sampling strategy was used to select the sample that received the SCID-P. For that reason, prevalence estimates could not be obtained directly from these data. In a forthcoming manuscript, Bayesian procedures will be applied to make such estimates.

\begin{tabular}{|c|c|c|c|}
\hline Laboratory Test & $\begin{array}{l}\text { No. of } \\
\text { Tests Done }\end{array}$ & Sensitivity, $\%$ & PPV, \% \\
\hline Papanicolaou test ${ }^{57}$ & 748871 & 80 & 73 \\
\hline Mammography ${ }^{58}$ & 27114 & 93 & 10 \\
\hline Hemoccult $^{59}$ & 1473 & 25 & 8 \\
\hline Prostate-specific antigen ${ }^{60}$ & 1002 & 81 & 24 \\
\hline Digital rectal examination ${ }^{61}$ & 2425 & 58 & 28 \\
\hline
\end{tabular}

subthreshold syndromes (abridged ${ }^{63}$ or borderline ${ }^{64}$ somatization disorder), which are prevalent in primary care practices, may have resulted in a usable screen.

Another subthreshold syndrome described in primary care is "minor depression". (not including dysthymia or chronic depression), which has a greater prevalence (3.6\% to $9.2 \%$ ) than does major depression ${ }^{2,65}$ and has significant associated morbidity in some dimensions that is similar to major depression..$^{7-9}$ Patients with minor depression also have an increased risk of developing major depression within 1 to 2 years. ${ }^{7.8}$ Although of apparent relevance to primary care, attempts to develop a screen for minor depression as part of the initial validation study were unsuccessful. Sensitivities were good, but despite a moderately high prevalence, the PPV for minor depression was too low (8\%) for screening nonselected patients.

The consistent results of the cross-validation study support the potential usefulness of these scales. The attenuation in sensitivities and other measures from the initial validation study is expected. Optimization of scales in one sample of subjects by selecting items to achieve certain desirable characteristics or to reduce scale length generally results in a reduction in performance when tested in a different sample. In addition, the results hold up despite significant differences in race, marital status, and education. This suggests generalizability of the SDDS-PC screen to broader ethnic and social groups than were present in the initial validation. However, the small sample size for some disorders in these two studies prevents further analysis of this issue.

The large refusal rates evident in these two studies limit the generalizability of the findings. Although there are mild differences in race and marital status between those who were screened and those who were finally interviewed, there may be other unmeasured characteristics that predict whether a person finished the study that may affect results.

The refusal rate is possibly an artifact of the study design. We asked active, busy, and often employed primary care patients to return for a face-to-face SCID-P interview on their own time. This may explain the low rates with which patients returned for this second phase of the evaluation. The higher refusal rates in the cross-validation study may have resulted from the complexity of adding the diagnostic interview modules to the protocol. These refusal rates may be reduced in future studies by paying participants and conducting the diagnostic interviews by telephone at times convenient to the patient. Such strategies are being used successfully in a second cross-validation of the SDDS-PC screen and diagnostic interview modules and have been described in other studies. ${ }^{54,55}$

Finally, the SDDS-PC screen has never been tested in its 16 -item version. Rather, these 16 items have been imbedded in longer versions. The effects of adjacent items within the questionnaire on patient responses are not predictable. Only testing of the 16-item version in a standalone format will indicate the true operating characteristics of this screen.

\section{CONCLUSIONS}

The SDDS-PC screen is a diagnostic aid comprising three components that has been developed to assist primary care physicians in identifying specific mental disorders. In this article, the findings relative to the first component of theSDDSPC, a brief (16-item) screening questionnaire ${ }_{3}$ are presented. The findings relative to the second component of the SDDS-PC, symptom-specific diagnostic modules (5-minute physician-administered structured interviews based on psychiatric diagnostic criteria specified in the DSM-III-R), will be presented in a forthcoming paper. An evaluation of patient progress based on the first two components of the SDDSPC (the screen and the diagnostic modules) can be recorded over time on a longitudinal tracking form, which accounts for the third component of the SDDS-PC.

The SDDS-PC screening questionnaire is designed to be self-administered by patients. It can detect from $62 \%$ to $90 \%$ of all patients with the disorders for which it screens. It also correctly classifies most of those without the disor- 
ders. The rate of false-positive test results is excellent for alcohol abuse or dependence, major depression, and panic disorder. Patients who screen positive for OCD or GAD also are likely to have some mental disorder worthy of physician recognition and intervention. Revision and further testing is necessary to reduce the number of false-positive results and to make these two scales more useful as first-stage screens.

This screen was designed for screening unselected patients, but it is expected that some physicians will prefer to use it for case finding in high risk groups (such as those with chronic medical problems or those expressing emotional distress), as has been recommended by Coulehan et $\mathrm{al}^{65}$ (depression screening). This also may be appropriate, but the screen has not been evaluated under such conditions.

The SDDS-PC screen offers evaluation of multiple mental disorders simultaneously, something currently available single-disorder screens are unable to do, thereby easing the burden of the primary care physician who is assessing patients with mental disorder symptoms. It has performance characteristics similar to other screening tests in primary care.

The entire SDDS-PC system is designed to assist in the treatment and follow-up of patients with mental disorders by helping the physician to target specific areas of concern. The use of the SDDS-PC as a training device in primary care residency programs was suggested by the family physicians in private practice who participated in this study and who noted their own experiences of learning about diagnoses they had not previously considered.

This is an interim report of a screening tool under development. A study is under way to upgrade the SDDS-PC screen with a new drug abuse and dependence scale and with revisions of the OCD and GAD scales. The screen and diagnostic interview modules have been revised to be consistent with the $D S M-I V,{ }^{47}$ the criterion standard for the study. Later studies are planned to assess the effects of using the SDDS-PC on patient outcomes and health care delivery.

Because of its potential to increase clinical efficiency, the SDDS-PC conceivably could become a significant component of a health care system reform initiative with both fee-for-service and managed care clinicians. Although the extent of its effect has yet to be determined, the SDDS-PC has additional potential to decrease health care use and the costs of medical care by identifying treatable mental disorders in primary care that can generate significant costs when they remain unrecognized.

\section{Accepted for publication October 25, 1994.}

Gerald L. Klerman, MD, was the initial principal investigator of this project until his death in April 1992. He served a prominent role in the design of the questionnaire and the studies. The three-part, symptom-driven system that constitutes the SDDS-PC was conceptualized at The Upjohn Co, which has sponsored and supported its development through its Pharmacosurveillance Unit (James A. Coleman, Director, and George B. Gross, Senior Project Manager) and its Health Care Economics and Policy Research Unit (Don Buesching, PhD, Senior Medical Sociologist).

Allen Frances, MD (Duke University, Durham, NC); Helena Kraemer, PhD (Stanford [Calif] University); and Larry
Culpepper, MD, and Vince Hunt (Brown University School of Medicine) provided advice. Christina Provencal (Brown University School of Medicine) and Lois Zemp (University of South Carolina, Columbia) were site project coordinators. Christina Provencal supervised the interviewer training at both sites. Robert Moore, DrPH (Columbia University, New York, NY), assisted in data collection and management, and Christina Hoven, DrPH (Columbia University), Laura Portera (Cornell University Medical Center, New York, NY), and Jessica Tse (Duke University) assisted in the data analysis. The participating physicians and the Advisory Council members (leaders from organizations with an interest in primary care mental health who met with the investigators and provided input into the project) are listed in the box below.

SDDS-PC is a trademark of The Upjohn Co.

Reprint requests to Ambulatory Services of Danville, 142 S Main St, Danville, VA 24541 (Dr Broadhead).

\section{Participating Physicians and Advisory Council Members}

\section{Participating Physicians}

Medical University of South Carolina, Charleston: David B. Alzenman, MD; Clive D. Brock, MD, ChB; David R. Garr, MD; Barry L. Hainer, MD; A. Cleve Hurson, MD; Robert C. Jones, MD; Steven M. Ornstein, MD; J. Howard Rupard, MD, PhD; Mark T. Simon, MD Brown University, Providence, RI: David P. Carter, MD; Colleen A. Cleary, MD; Gary M. Cummins, MD; Arthur A. Frazzano, MD; Margaret S. Lytton, MD; Margaret Tryforos, MD; and Ira G. Warshaw, MD.

\section{Advisory Council}

Macaran Baird, MD (State University of New York Health Science Center, Syracuse); Dave Baron, DO (American Osteopathic Association, Chicago, Ill); Susan Blumenthal, MD (Assistant Surgeon General); Jorge A. Costa e Silva (World Health Organization, Geneva, Switzerland); Leah Dickstein, MD (University of Louisville [Ky] School of Medicine); Mary Jane England, MD (Washington [DC] Business Group on Health); Shervert H. Frazier, MD (McLean Hospital, Bethesda, Md); Roman H. Hendrickson, MD (American Academy of Family Physicians, Kansas City, Mo); Norman B. Kahn, MD (American Academy of Family Physicians); Kathryn Magruder, PhD (National Institute of Health, Bethesda); Harold A. Pincus, MD (American Psychiatric Association, Washington, DC); Darrell A. Regier, MD, MPH (National Institute of Mental Health, Bethesda); Rene Rodriguez, MD (National Confederation of Hispanic American Medical Association, Jackson Heights, NY); Richard Ruppert, MD (American Society of Internal Medicine, Washington, DC); Norman Sartorius, MD (World Health Organization); Richard Steinhilber, MD (Cleveland [Ohio] Clinic Foundation); William Van Stone, MD (Department of Veterans Affairs, Washington, DC); Elinor Walker (Agency for Health Care Policy and Research, Rockville, Md); Paul Young, MD (American Board of Family Practice, Lexington, Ky). Their presence on the Advisory Council in no way signifies an endorsement by these individuals or organizations. 
32. Campbell TI. Is screening for mental health problems worthwhile in family practice? an opposing view. J Fam Pract. 1987;25:184-187.

1. Hoeper EW, Nycz GR, Regier DA, Goldberg ID. Diagnosis of mental disorder in adults and increased use of health services in four outpatient settings. $A m ~ J$ Psychiatry. 1980;137:207-210

2. Barrett JE, Barrett JA, Oxman TE, Gerber PD. The prevalence of psychiatric disorders in a primary care practice. Arch Gen Psychiatry. 1988:45:11001106.

3. Kessler LG, Cleary PD, Burke JJ. Psychiatric disorders in primary care: results of a follow-up study. Arch Gen Psychiatry. 1985;42:583-587.

4. Schurman RA, Kramer PD, Mitchell JB. The hidden mental heaith network: treatment of mental illness by nonpsychiatrist physicians. Arch Gen Psychiatry. 1985;42:89-94.

5. Regier DA, Narrow WE, Rae DS, Manderscheid RW, Locke BZ, Goodwin FK. The de facto US mental and addictive disorders service system: epidemiologic catchment area prospective 1-year prevalence rates of disorders and services. Arch Gen Psychiatry. 1993;50:85-93.

6. Shapiro S. Skinner EA, Kessler LG, et al. Utilization of health and mental health services: three Epidemiologic Catchment Area sites. Arch Gen Psychiatry. 1984; 41:971-978

7. Wells KB, Stewart $A$, Hays RD, et al. The functioning and well-being of depressed patients: results from the Medical Outcomes Study. JAMA. 1989;262: 914-919.

8. Broadhead WE, Blazer DG, George LK, Tse C-KJ. Depression, disability days, and days lost from work in a prospective epidemiologic survey. JAMA. 1990; 264:2524-2528

9. Johnson J, Weissman MM, Klerman GL. Service utilization and social morbidity associated with depressive symptoms in the community. JAMA. 1992; 267:1478-1483

10. Stoudemire A, Frank R, Hedemark N, Kamlet M, Blazer D. The economic burden of depression. Gen Hosp Psychiatry. 1986;8:387-394.

11. Rice DP, Miller LS. The economic burden of affective disorders. Presented at the International Workshop on Costs and Assessment in Psychiatry: The Costs of Affective Disorders; October 12-13, 1992; Venice, Italy.

12. DuPont RL, Shiraki S, Rice DP, Miller LS, Rowland C, Harwood H. The economic costs of anxiety disorders. Presented at the National Institute of Mental Health; February 2, 1993; Bethesda, Md.

13. Nielsen AC, Williams TA. Depression in ambulatory medical patients: prevalence by self-report questionnaire and recognition by nonpsychiatric physicians. Arch Gen Psychiatry. 1980;37:999-1004.

14. Ormel J, van den Brink W, Koeter MW, et al. Recognition, management and outcome of psychological disorders in primary care: a naturalistic follow-up study. Psychol Med. 1990;20:909-923.

15. Jencks SF. Recognition of mental distress and diagnosis of mental disorder in primary care. JAMA. 1985;253:1903-1907.

16. Beardsley RS, Gardocki GJ, Larson DB, Hidalgo J. Prescribing of psychotropic medication by primary care physicians and psychiatrists. Arch Gen Psychiatry 1988:45:1117-1119.

17. Reifler BV, Ward NG. A comparison of the use of tricyclic antidepressants by psychiatrists and non-psychiatric physicians. Int J Psychiatry Med. 1980;10: 41-49.

18. Larson DB, Lyons JS, Hohmann AA, Beardsley RS, Hidalgo J. Psychotropics prescribed to the US elderly in the early and mid-1980's: prescribing patterns of primary care practitioners, psychiatrists, and other physicians. Int $J$ Geriatr Psychiatry. 1991;6:63-70.

19. Wells KB, Goldberg G, Brook R, Leake B. Management of patients on psychotropic drugs in primary care clinics. Med Care. 1988;26:645-656.

20. Uhlenhuth EH, Balter MB, Mellinger GD, Cisin IH, Clinthorne J. Symptom checklist syndromes in the general population: correlations with psychotherapeutic drug use. Arch Gen Psychiatry. 1983;40:1167-1173.

21. Von Korff M, Shapiro S, Burke JD, et al. Anxiety and depression in a primary care clinic. Arch Gen Psychiatry. 1987;44:152-156.

22. Goldberg DP. The Detection of Psychiatric IIness by Questionnaire. London, England: Oxford University Press: 1972.

23. Derogatis LR, Lipman RS, Rickels K, Covi L. The Hopkins Symptom Checklist: a self-report symptom inventory. Behav Sci. 1974;19:1-15.

24. Skuse $D$. Williams $P$. Screening for psychiatric disorder in general practice. Psychol Med. 1984;14:365-377.

25. Zich JM, Attkisson CC, Greenfield TK. Screening for depression in primary care clinics: the CES-D and the BDI. Int J Psychiatry Med. 1990;20:259-277.

26. Cleary PD, Bush BT, Kessler LG. Evaluating the use of mental health screening scales in primary care settings using receiver operating characteristic curves. Med Care. 1987:25(suppl 12):S90-S98

27. Kavan MG, Pace TM, Ponterotto JG, Barone EJ. Screening for depression: use of patient questionnaires. Am Fam Physician. 1990;41:897-904

28. Beck AT, Beck RW. Screening depressed patients in a family practice. Postgrad Med. 1972;17:81-85.

29. Zung WWK. A self-rating depression scale. Arch Gen Psychiatry. 1965;12:63-70.

30. Zung WWK. A rating instrument for anxiety disorders. Psychosomatics. 1971; 12:164-167.

31. Frame PS. Screening procedure in primary care: history and uses. In: Attkisson CC, Zich JM, eds. Depression in Primary Care: Screening and Detection. New York, NY: Routledge; 1990:12-20.

33. Kamerow DB. Is screening for mental health problems worthwhile in family practice? an affirmative view. J Fam Pract. 1987;25:181-183.

34. Coulehan JL, Schulberg HC, Block MR. The efficiency of depression questionnaires for case finding in primary medical care. J Gen Intern Med. 1989;4:541-547.

35. Canadian Task Force on the Periodic Health Examination. Periodic health examination, II: 1985 update. Can Med Assoc J. 1986;134:724-729.

36. US Preventive Services Task Force. Guide to Clinical Preventive Services: An Assessment of the Effectiveness of 169 Interventions. Baltimore, Md: Williams \& Wilkins; 1989

37. Linn LS, Yager J. Screening of depression in relationship to subsequent patient and physician behavior. Med Care. 1982;20:1233-1239.

38. Linn LS, Yager J. The effect of screening, sensitization, and feedback on notation of depression. J Med Educ. 1980;55:942-949.

39. Moore JT, Silimperi DR. Bobula JA. Recognition of depression by famity medicine residents: the impact of screening. J Fam Pract. 1978;7:509-513.

40. Magruder-Habib K, Zung WWK, Feussner JR. Improving physicians recognition and treatment of depression in general medical care: results of randomized clinical trial. Med Care. 1990;28:239-250.

41. Zung WWK, Magill M, Moore JT, et al. Recognition and treatment of depression in a family medicine practice. J Clin Psychiatry. 1983;44:3-6.

42. Ormel J, Koeter MW, van den Brink W, van de Willige G. Recognition, management, and course of anxiety and depression in general practice. Arch Gen Psychiatry. 1991;48:700-706.

43. Spitzer RL, Williams JBW, Kroenke K, et al. The PRIME-MD 1000 study: validation of a new system for diagnosing mental disorders in primary care. Presented at the Seventh Annual NIMH International Research Conference on Mental Health Problems in the General Health Sector; September 21, 1993; McLean, Va.

44. American Psychiatric Association. Diagnostic and Statistical Manual of Mental Disorders, Revised Third Edition. Washington, DC: American Psychiatric Association; 1987.

45. Spitzer RL, Williams JBW, Gibbon M, First M. The Structured Clinical Interview for DSM-III-R (SCID), I: history, rationale, and description. Arch Gen PSychiatry. 1992;49:624-629.

46. Williams JBW, Gibbon M, First MB, et al. The Structured Clinical Interview for DSM-III-R (SCID), II: multisite test-retest reliability. Arch Gen Psychiatry. 1992; 49:630-636.

47. American Psychiatric Association. Diagnostic and Statistical Manual of Mental Disorders, Fourth Edition. Washington, DC: American Psychiatric Association; 1994.

48. Endicott J, Spitzer RL, Fleiss JL, Cohan J. The Global Assessment Scale. Arch Gen Psychiatry. 1976;33:766-770.

49. Burnam MA, Wells KB, Leake B, Landsverk J. Development of a brief screening instrument for detecting depressive disorders. Med Care. 1988:26:775-789.

50. Tarlov AR, Ware JE, Greentield S, Nelson EC, Perrin E, Zubkoff M. The Medical Outcomes Study: an application of methods for monitoring the results of medical care. JAMA. 1989:262:925-930.

51. Ewing JA. Detecting alcoholism: the CAGE questionnaire. JAMA. 1984;252 1905-1907.

52. Kraemer HC. Evaluating Medical Tests: Objective and Quantitative Guidelines. Newbury Park, Calif: Sage Publications Inc; 1992.

53. Sobin C, Weissman MM, Goldstein RB, et al. Diagnostic interviewing for family studies: comparing telephone and face-to-face methods for the diagnosis of lifetime psychiatric disorders. Psychiatr Genet. 1993;3:227-233.

54. Simon GE, Revicki D, VonKorff. Telephone assessment of depression severity. $J$ Psychiatr Res. 1993;27:247-252.

55. Paulsen AS, Crowe RR, Noyes R, Pfohl B. Reliability of the telephone interview in diagnosing anxiety disorders. Arch Gen Psychiatry. 1988:45:62-63.

56. Hough RL, Landsverk JA, Jacobson GF. The use of psychiatric screening scales to detect depression in primary care patients. In: Attkisson CC, Zich JM, eds. Depression in Primary Care: Screening and Detection. New York, NY: Routledge; 1990:139-154.

57. Soost $H J$, Lange $H J$, Lehmacher W, Ruffing-Kullman B. The validation of cervical cytology: sensitivity, specificity, and predictive values. Acta Cytol. 1991; 35:8-14.

58. Sickles EA, Ominsky SH, Sollitto RA, Galvin HB, Monticciolo DL. Medical audit of a rapid-throughput mammography screening practice: methodology and results of 27,114 examinations. Radiology. 1990;175:323-327.

59. Bang KM, Tillett S, Hoar SK, Blair A, McDougall V. Sensitivity of fecal hemoccult testing and flexible sigmoidoscopy for colorectal cancer scrèen. J Occup Med. 1986;28:709-713.

60. Littrup PJ, Lee F. Mettlin C. Prostate cancer screening: current trends and future implications. CA Cancer J Clin. 1992;42:198-211.

61. Mettlin CJ, Lee F, Drago J, Murphy GP. The American Cancer Society National Prostate Cancer Detection Project: findings on the detection of early prostate cancer in 2,425 men. CA Cancer J Clin. 1991;67:2949-2958.

62. Galen RS, Gambino SR. Beyond Normality: The Predictive Value and Efficiency of Medical Diagnoses. New York, NY: John Wiley \& Sons Inc; 1975.

63. Escobar JI, Burnam MA, Karno M, Forsythe A, Golding JM. Somatization in the community. Arch Gen Psychiatry. 1987:44:713-718.

64. deGruy F, Columbia L, Dickinson P. Somatization disorder in a family practice. $J$ Fam Pract. 1987;25:45-51.

65. Coulehan JL, Schulberg HC, Block MR, Janosky JE, Arena VC. Depressive symptomatology and medical co-morbidity in a primary care clinic. Int $J$ Psychiatry Med. 1990;20:335-347. 